\title{
Identificación de peligros microbiológicos en vegetales frescos
}

\section{Identificaction of microbiological treets in fresh vegetabbles}

\section{Nivian Montes de Oca}

Centro Nacional de Sanidad Agropecuaria (CENSA, Apartado 10, San José de las Lajas, Mayabeque, Cuba.), nivian@censa.edu.cu

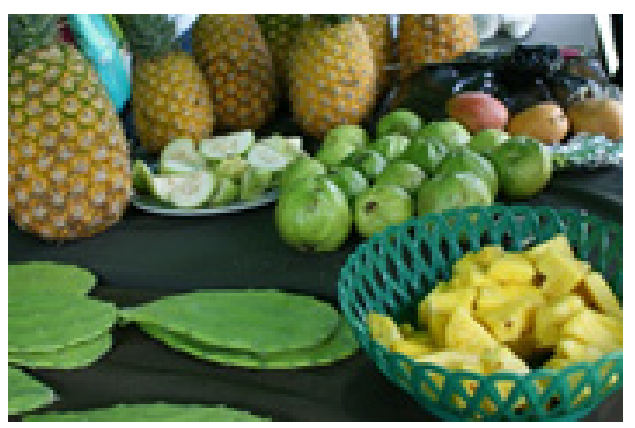

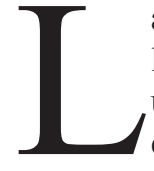
as hortalizas frescas son productos que se comercializan listos para su consumo. Estos alimentos son una fuente óptima de fibras, vitaminas, minerales e hidratos de carbono, y en esa condición forman parte esencial de una alimentación equilibrada. Su consumo ha mostrado un aumento a nivel mundial y con este se ha incrementado el número de brotes de enfermedades asociadas a este tipo de productos.

Amplia evidencia científica confirma que las frutas y hortalizas frescas no son contaminadas normalmente con patógenos humanos. Estos microorganismos patógenos son finalmente introducidos en los productos frescos desde una fuente externa.

En este sentido, se han dirigido esfuerzos tendientes a generar medidas que contribuyan a minimizar el riesgo de enfermedades asociadas al consumo de estos alimentos. Las medidas más efectivas, se enfocan a trabajar desde la prevención, empezando por el campo con las Buenas Prácticas Agrícolas, avanzando en los diferentes eslabones de la cadena, que involucran etapas de procesamiento y transformación a nivel industrial, transporte y distribución, hasta llegar al consumidor final; allí cobran importancia las Buenas Práctica de Manufactura (3).

En Cuba la venta de vegetales frescos se realiza bajo condiciones que pueden propiciar fuentes de contaminaciones con microorganismos patógenos. Existen varios grupos de científicos trabajando estos temas, que van desde el diagnóstico de los patógenos hasta la formulación de requisitos organizados en Guías de Buenas Prácticas Agrícolas y Buenas Prácticas de Higiene, sin embargo aún no se cuenta con una sólida implementación y educación que permita una prevención eficaz de las ETAs por consumo de vegetales frescos.
En un estudio realizado en seis escenarios del país que comprenden a organopónicos, fincas suburbanas y puntos de ventas particulares, se encontró la presencia de Staphylococcus spp. (94.1\%), Salmonella spp. (52.9\%), Listeria spp. (64.7\%) y, E. coli $\mathrm{O} 157$ (29.4\%) en muestras de lechuga, col, acelga, col china y espinaca.

Este resultado motivó la realización de encuestas, entrevistas y revisión de la cadena de producción y venta utilizando listas de chequeo con requisitos de varios documentos internacionales como el aprobado por la Food and Drugs Administration de los Estados Unidos, los requisitos definidos por GLOBALGAP en su lista de chequeo del año $2011 \mathrm{y}$ la guía de la FAO del 2007, así como elementos propios de las condiciones de los escenarios estudiados. Su aplicación demostró que solo se cumplía con el $44 \%$ de los requisitos evaluados.

Culminada esta etapa del trabajo, se seleccionó una finca suburbana donde se aplicaron las BPA. Un año después se realizaron nuevas evaluaciones a las hortalizas obtenidas y comercializadas, donde se encontró disminución sustancial de en la presencia de microorganismos patógenos. En las muestras analizadas no se detectó presencia de Salmonella spp., Escherichia coli. Los porcientos de Listeria spp., Escherichia coli y Staphylococcus coagulasa positivos fueron $40 \%, 53.3 \%$ y $75 \%$ respectivamente. Además se determinó la presencia de Escherichia coli en muestras de suelo, agua de riego y compost, sin embargo, no se aisló esta bacteria de las muestras de vegetales analizadas.

Todos estos elementos se constituyeron en una Guía de Buenas Prácticas Agrícolas, que lograra ser el punto de partida para llegar a un documento oficial para el país en este campo. 


\section{COMUNTCACIOON}

\section{REFERENCIAS BIBLIOGRÁFICAS}

Rushing, JW; Bihn, EA; Brown, AE; Hill, T; Jones, JW; Martin Lo, Y; McGarry, SA; Saltsman, J. 2012. Mejorando la seguridad y calidad de frutas y hortalizas frescas: Un manual de capacitación para los capacitadores. Derechos de Autor@ Universidad de Maryland. (en línea). Consultado 31 de mar. 2014. Disponible en http://jifsan.umd.edu/docs/gaps/es/Manual\%20Completo.pdf.

Suarez, SJ; Gómez, LM. 2013. Evaluación de un producto a base de ácidos orgánicos frente a E. coli y Salmonella spp, en la desinfección de lechuga fresca. Revista Alimentos Hoy. 22(29):20-32.

FDA (Food and Drugs Administration, US). 1998. Guía para reducir al mínimo el riesgo microbiano en los alimentos,en el caso de frutas y vegetales frescos. (en línea). Consultado 31 de mar 2014. Disponible en http://www.fda.gov/downloads/Food/GuidanceRegulation/UCM186594.pdf.

GLOBALGAP. 2011. Checklist integrated farm assurance fruit and vegetables. (en línea). Consultado 31 de mar 2014. Disponible en http://www.fresq.nl/archvr/Downloads/Checklist_IFA_Fruit and Vegetables_English_Version_Interim_Final V4_0 Jan2011.pdf.

Izquierdo, J; Rodriguez, M; Duran, M. 2007. Guía de buenas práctica agrícolas para la agricultura familiar. FAO $\overline{-}$ - 2007 . ISBN 97892-5-305693-4. (en línea). Consultado 31 mar. 2014. Disponible en http://www.fao.org.co/manualbpa.pdf. 